\title{
Rapid Screening of Operational Freshwater Availability Using Global Models
}

\author{
M. W. Straatsma ${ }^{1}$ - P. T. M. Vermeulen ${ }^{2}$. \\ M. J. M. Kuijper ${ }^{2}$ - M. Bonte ${ }^{3}$ - F. G. M. Niele ${ }^{3}$. \\ M. F. P. Bierkens ${ }^{1,2}$
}

Received: 18 December 2015 / Accepted: 7 April 2016/

Published online: 10 May 2016

(C) The Author(s) 2016. This article is published with open access at Springerlink.com

\begin{abstract}
Freshwater shortage already affects large parts of the world, and is expected to increase rapidly over the coming decades as a result of increased water demands and the impacts of climate change. Global-scale water risk or stress maps are available online, but these lack quantitative information on local freshwater availability, rendering them unsuitable for water risk assessment from an operational perspective, i.e. when comparing water availability to a specific quantified water demand (in $\mathrm{m}^{3} \mathrm{~s}^{-1}$ rather than generic risk indicators). Therefore, our main goal was to develop a rapid screening method to estimate current and future operational freshwater availability using global-scale models. Operational Freshwater Availability (OFWA) was computed using the PCR-GLOBWB global hydrology and water resources model, coupled to a global MODFLOW groundwater model. PCR-GLOBWB was forced with rainfall and temperature fields from the IPSL-CM5A-LR climate model under the RCP6.0 climate scenario, with water demands based on the SSP2 socio-economic scenario. Unique to our study are the downscaling of the coupled PCR-GLOBWB-MODFLOW model to $90 \mathrm{~m}$ resolution and the provision of quantitative estimates on long term trends in operational freshwater availability. Our results showed a high, i.e. operationally relevant, accuracy for operational surface water availability, while the uncertainty about operational groundwater availability remained high due to limited availability of subsurface data. With this method, we developed a modelling capacity for rapidly generating scenario-based water availability projections with operational relevance in a rigorous, systematic way, such that it
\end{abstract}

Electronic supplementary material The online version of this article (doi:10.1007/s11269-016-1327-5) contains supplementary material, which is available to authorized users.

M. W. Straatsma

m.w.straatsma@uu.nl

1 Faculty of Geosciences, Department of Physical Geography, Utrecht University, PO Box 80115, 3508 TC Utrecht, The Netherlands

2 Deltares, PO Box 85467, 3584 CB Utrecht, The Netherlands

3 Shell Global Solutions, PO Box 60, 2280 AB Rijswijk, The Netherlands 
enables like-for-like comparisons. Further refinement is required for accurate estimates of operational groundwater availability.

Keywords Freshwater availability · Groundwater availability · Rapid assessment . Global models · Downscaling

\section{Introduction}

Climate and socioeconomic change affect the amount of water available for irrigation, industry and households, leading to high freshwater stress in large parts of the globe (Haddeland et al. 2014; Vörösmarty et al. 2000). The urgency of water stress has been underpinned by a large number of global studies on historic and future water stress based on global hydrological models (Cai and Rosegrant 2002; Döll et al. 2003; Falloon and Betts 2010; Gain and Wada 2014; Hanasaki et al. 2008; Van Beek et al. 2011; Wada et al. 2011). In 'Global Risks 2015', the World Economic Forum ranks 'Water crises' number eight in terms of likelihood and number one in terms of impact when related to the main economic, environmental, geopolitical, societal and technological global risks identified. Water scarcity is expected to increase rapidly over the coming decades due to both higher demands and impacts of climate change (2030WRG 2009).

Water risks are assessed at multiple scales, with global overviews and local studies at the extreme ends of the spectrum. Global scale hydroclimatic data become more and more available as web-based services (Bierkens 2015), but there still exists a large gap between what global services provide and the detail and accuracy required by local operations and decision makers in assessing and, if identified, mitigating water-related risks. A well-known example of a web-based service, the Aquaduct Water Risk Atlas (WRI 2013), features twelve risk indices categorized by water quantity risk, water quality risk, and regulatory and reputational risk (Gassert et al. 2012). It visualizes, for example, groundwater stress (Gleeson et al. 2012), drought severity (Sheffield and Wood 2007), and upstream storage (Lehner 2011). While these maps provide useful information on water stress at river basin scale, they do not fulfill the need for quantitative data on freshwater availability for local water users, including industrial and civil utilities being more interested in a volumetric metric $\left(\mathrm{m}^{3} \mathrm{~s}^{-1}\right)$ rather than a dimensionless risk indicator. Schornagel et al. (2012), for example, presented a water accounting approach to enable the assessment of water-related risks at the level of an individual industrial asset. Their method is based on the concept of "economic water stress," which occurs when the cost of adaptation to - emerging - water availability constraints limits the industrial operation and requires estimates of sustainable water availability within the basin. In view of the rapidly developing gap between water supply and demand (2030WRG 2009; Idowu et al. 2012) it is crucial to evaluate physical water availabilities within the context of both water demand and water supply scenarios. Local water availability and risk is estimated regularly by consulting companies, but these results are rarely disclosed. Inter-comparison between such studies is hampered by the use of different methodologies and modeling choices of climate change scenario, climate model, and water demand projection. Inter-comparison of water availabilities on a like-for-like basis thus becomes difficult if not impossible within the context of long-term water demand and supply scenarios.

A rapid screening tool with global reach and local screening accuracy would, therefore, be powerful. Such a tool could accelerate quantitative assessments of water availability 
projections within the context of long-term "water change" scenarios with operational relevance in a systematic way (to make water-related risk assessments comparable on a like-forlike basis) with an acceptable effort. This would especially be valuable in regions with limited data or lacking existing water availability models. Furthermore, the capacity to generate longterm water availability projections on the basis of IPCC scenarios for climate change and socio-economic development in a methodologically rigorous way is only sparsely built into local hydrological models. Therefore, our main goal is to develop and test a rapid screening method to estimate current and future operational freshwater availability using global-scale models. "Operational" relates in this context to the operation of a large asset, such as public water utility companies or industrial assets.

In this paper, we present a method to determine the so-called Operational Freshwater Availability (OFWA) within the context of IPCC AR5 scenario-based change patterns for water demand and supply. OFWA was computed using the PCR-GLOBWB global hydrology and water resources model, coupled to a global MODFLOW groundwater model. We applied the method to two study areas: one in The Netherlands, and one in the United States. The quality of the freshwater was not taken into account in this study. In addition, we did not assess the availability of brackish and salt water resources.

\section{Study Areas}

For this study, two areas were chosen in deltaic regions: the Lower Rhine-Meuse Estuary (LRME) area in The Netherlands, and the Lower Buffalo Bayou (LBB) area, in the USA (Online Resource 1; Fig. S1). We used a square asset extent for this study, with a size of $5 \mathrm{~km}^{2}$, considered representative of a large civil or industrial facility or well field. Size, shape, or position, could easily be adjusted to represent the shape of an actual asset anywhere on the globe. The graticules shows the individual cells at 5 arcminute $\left(5^{\prime}\right)$ resolution, the computational resolution of PCR-GLOBWB. LRME is close to the mouth of the Rhine and the Meuse Rivers, with river runoff (discharge) gauging stations at Lobith at the Dutch-German border for the runoff of the Rhine River, and at Lith for the Meuse River (Table S1). LBB borders the Buffalo Bayou, and is also nearby the San Jacinto River, and only has a single gauging station in the West Fork of the San Jacinto River. LRME is fed by the medium sized Rhine and Meuse Rivers, which drain an area with a maritime temperate climate. LBB derives its water from much smaller watersheds (Table S1) with a warm temperate climate.

\section{Methods: Defining and Computing Operational Freshwater Availability}

Operational freshwater availability (OFWA) consists of two components: (1) operational surface water availability, and (2) operational groundwater availability. OFWA is defined here as the total amount of freshwater available at an asset that can be sustainably abstracted from nearby rivers and the underlying aquifer. This definition is operationally relevant, and quantitative, as opposed to the widely used global stress indicators. Available water results from hydrological supply through surface water and aquifers minus environmental flow requirements and upstream freshwater demands. This approach provides a first screening of the OFWA, which would be followed by an impact assessment. Nearby rivers and the underlying aquifer are defined as a local 5 by 5 cell window at $5^{\prime}$ spatial resolution around the asset. This 
is approximately 45 by $45 \mathrm{~km}$ at the equator, but may be altered in other applications. The definition assumes that water within this window is available for the asset, whether or not existing infrastructure is in place to transport water from the nearby rivers to the asset. Canals are not included as they are not natural flow paths and do not follow the natural terrain slope. We realize this is an omission, but we are looking for measures that are globally attainable. Currently, artificial redistribution networks are not globally mapped. The relationship between operational freshwater availability, operational surface water availability and operational groundwater availability is clarified below. In section 3.4, we summarize the modeling setup.

\subsection{Operational Surface Water Availability}

Operational surface water availability (OSWA) is defined here as the river runoff (considering existing water demands) minus environmental flow requirements. OSWA is limited by combined physical and regulatory constraints, where the regulatory constraint is linked to the definition of the minimum environmental flow required to maintain a healthy ecosystem. Figure 1a illustrates the different components of the OSWA for a single year: (1) the pristine runoff, being the river runoff that would be present without any water demands of human origin in the river basin; it was derived from a PCR-GLOBWB run without the inclusion of agricultural, industrial and domestic water abstractions. (2) The actual river runoff, being the pristine runoff minus the net water consumption in the watershed upstream from the asset, and (3) the environmental flow requirement. In this graphical example, the environmental flow requirements exceed the river runoff from October through December, indicating a water shortage in this period. The water shortage increased due to the basin water demands, but even under pristine conditions a temporary shortage can occur in dry years.
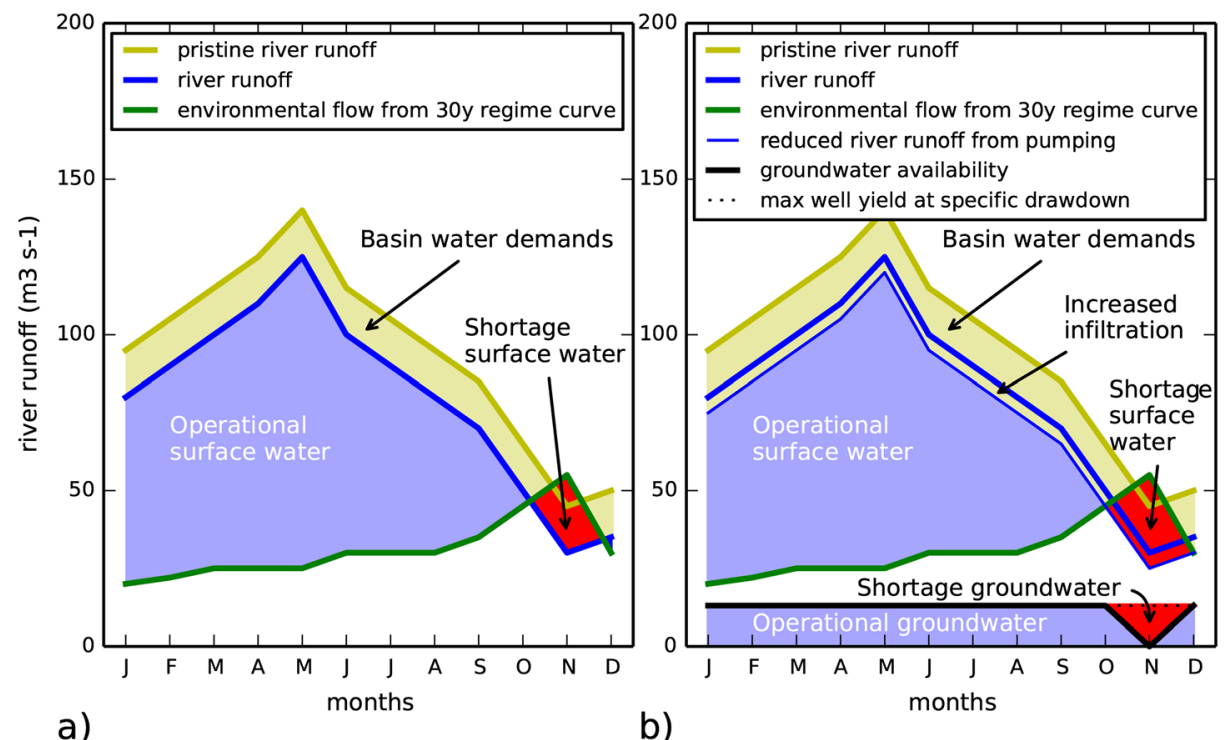

Fig. 1 Operational Freshwater Availability at the asset based on hypothetical data. Blue shading is available water, red shading indicates a water shortage. a Available surface water consists of the river runoff minus environmental flow requirements. b Two components of the operational freshwater availability surface water and groundwater. River runoff is reduced due to increased infiltration caused by the lower groundwater head. No pumping of surface and groundwater is allowed when the river runoff is lower than the environmental flow 
Environmental flow requirements (EFR) strongly determine OSWA, but there is no general agreement on how much the environmental flow should be (Acreman and Dunbar 2004). We defined environmental flow in this study in a globally consistent way as a percentage of the regime graph of the simulated pristine river runoff over a 30 year historic period (1980-2010). The regime graph depicts long term average discharge per month and the 30 year period was chosen to filter out annual and interannual variations. The advantage of this definition is that it is not affected by the current water demands, includes temporal variation over the year, and does not vary due to future climate change. Note that this environmental flow requirement does not factor in shipping, or minimum river flows to limit salt intrusion in deltas. Percentages for environmental flow range from 10 to $60 \%$ (Souchon and Keith 2001; Tennant 1976). Values around $30 \%$ are within the range commonly used in international studies (Tharme 2003). To assess the effect of different percentages in the definition of environmental flow on OSWA, we evaluated 10 and $30 \%$.

\subsection{Operational Groundwater Availability}

The operational groundwater availability (OGWA) at the asset is the hydrogeologically constrained groundwater yield, given a maximum allowed drawdown over the full spatial extent of the asset, and limited by environmental flow requirements in rivers having a connection to the aquifer. Similar to OSWA, OGWA is limited by combined physical and regulatory constraint due to the definition of both maximum drawdown and environmental flow constraints. No global overview is available on regulatory constraints, and the allowed drawdown is site-specific, depending on impacts to other users, rivers, or land settlements. Therefore, a set of ten increasingly deeper drawdowns was evaluated in this study. Note that this assessment does not give direct information on the number of groundwater wells that would be required to extract the volume of available groundwater.

\subsection{Operational Freshwater Availability}

Operational freshwater availability (OFWA) is defined as OSWA plus OGWA minus increased infiltration of surface water induced by groundwater extraction to avoid double counting. The effect of increased surface water infiltration is illustrated in Fig. 1b. The figure shows the same pristine river runoff, actual river runoff including upstream demands, and environmental flow as Fig. 1a, but the effects of groundwater extraction have been added. This shows how groundwater pumping reduces river flow. The lower river runoff reduces the available surface water, and increases the duration of the period that the environmental flow requirements are not fulfilled. On the other hand, additional groundwater becomes available, represented as the blue fill at the bottom of the graph. During the period of violation of the environmental flow requirements, it is assumed that no groundwater may be extracted.

\subsection{Computation of Operational Freshwater Availability}

The separate steps to compute OFWA are illustrated in Fig. 2. Modeling choices were based on the objective to obtain a central or 'middle of the road' estimate of the OFWA, which means that we did not use extreme climate models, extreme climate change scenarios, or extreme socioeconomic scenarios for the future. To compute operational freshwater availability, we combined two hydrologic models: PCR-GLOBWB for the surface and shallow subsurface hydrology, and MODFLOW-iMOD for the deep groundwater. 


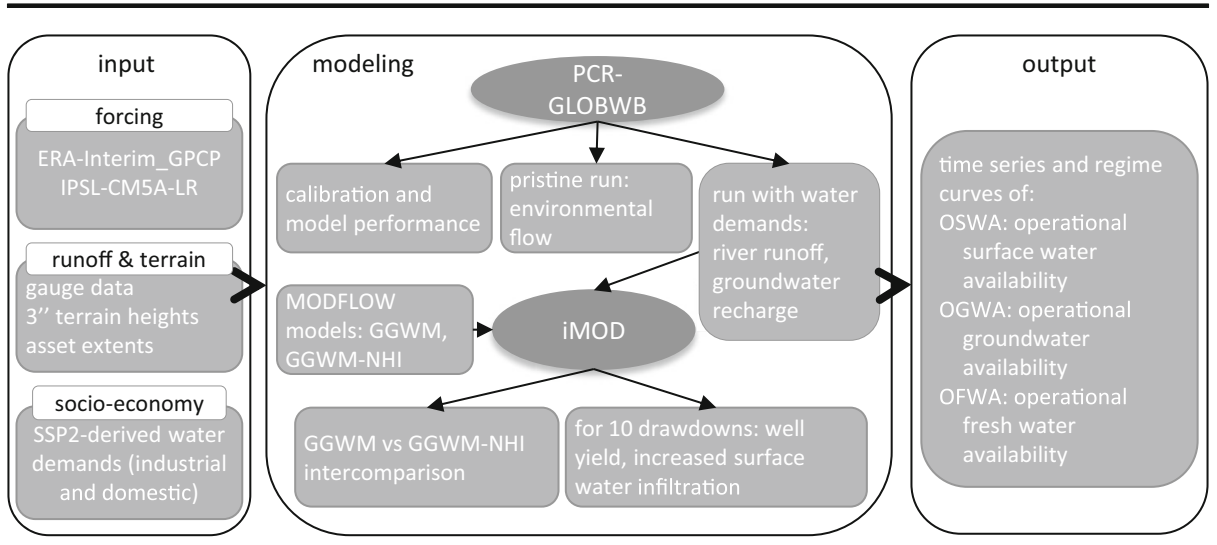

Fig. 2 Flow chart of the input and modeling steps to determine operational freshwater availability

The details of the model implementation, precipitation correction, and downscaling are provided in the supplementary material (Online Resource 1). In brief: PCR-GLOBWB simulates water storages and fluxes of the terrestrial part of the hydrological cycle. It is a grid-based global hydrological model (Van Beek et al. 2011) with 5' cells in latitude and longitude. For each grid cell, PCR-GLOBWB simulates moisture storage in two vertically stacked upper soil layers, as well as the water exchange between the soil, the atmosphere and the underlying shallow groundwater reservoir. We simulated the whole river basin upstream of the assets and PCR-GLOBWB routed the baseflow, interflow and surface runoff to the outlet of the catchment. PCR-GLOBWB was forced using two climate forcings. Firstly, for model calibration over the 1980-2010 period, we used the ERA-Interim reanalysis data that were rescaled using the Global Precipitation Climatology Project (GPCP) (Adler et al. 2003; Huffman et al. 2009). We will therefore refer to this forcing as ERA-Interim_GPCP. Secondly, we used data from the Coupled Model Intercomparison Project (CMIP5) (Taylor et al. 2012) for the period 1980-2065 to determine OSWA. Specifically, we chose the IPSL-CM5A-LR coupled Global Circulation Model (Dufresne et al. 2013) using the RCP6.0 climate scenario. Water demands are driven by socio-economic factors, based on the Shared Socio-economic Pathways (SSP2) scenario (Vuuren et al. 2014). The river runoff was calibrated on measured discharges by applying a basin-specific correction factor using the long term mean discharge. Validation was carried out on monthly time series for the PCR-GLOBWB run with the ERAInterim_GPCP forcing.

For the deep groundwater, PCR-GLOBWB was coupled to a global groundwater model (GGWM) built in MODFLOW (Harbaugh et al. 2000). This simulates lateral shallow and deep groundwater flows, based on a single layer representation of the subsurface (de Graaf et al. 2014). The base data for the aquifer properties were the high resolution Global Lithological Map (GLiM) (Hartmann and Moosdorf 2012) and a global map of permeability (Gleeson et al. 2011). We increased the resolution of the PCR-GLOBWB output by a factor 100 in cell length, from $5^{\prime}$ to 3 arcseconds (3") to maintain a high level of spatial detail in the GGWM. OGWA was based on computations with the downscaled global groundwater model. The steady-state global groundwater model was imported into iMOD modeling software (Vermeulen and Minnema 2015) to facilitate the implementation of the set of ten drawdowns. The imported steady state model was converted to a transient model using entries for recharge and surface water elevations from PCR-GLOBWB on a monthly timescale between 1980 and 2065. After 
OSWA and OGWA were computed, OFWA was derived in a postprocessing step. The well yields of the GGWM were compared against the Dutch National Hydrological Instrument for the LRME. The subsoil parameters of the NHI model were re-projected to 3" to substitute the subsoil parameters of the GGWM model. We will refer to this model as GGWM-NHI.

\section{Results}

Here we describe the outcome of the model validation and intercomparison. Subsequently, we provide details on the components of operational freshwater availability for the two study areas.

\subsection{PCR-GLOBWB Validation and Well Yield Comparison}

For PCR-GLOBWB, the validation procedure resulted in a rainfall correction factor on the mean river runoff that ranged from 0.77 for the Rhine River to 0.97 for the West Fork of the San Jacinto River for the ERA-Interim_GPCP forcing (Table 1). Using the corrected rainfall fields, the Nash-Sutcliffe (NS) model efficiency (Nash and Sutcliffe 1970) varied between 0.09 for the San Jacinto to 0.58 for the Rhine and Meuse River. The main reason for the lower NS coefficient for the San Jacinto was the size of the catchment and the mean river runoff that is a factor ten lower for the San Jacinto River compared to the Rhine River. In addition, a series of floods was not captured in the rainfall data (e.g. 1994, and 1998), which negatively impacted the NS coefficient. For the Rhine and Meuse River the peaks were also slightly underestimated, but the main model error for these rivers came from the timing of the discharge. This showed a delay of around 2 months in the average peak discharge. See Fig. S4 for the time series and regime graphs for all three stations. The IPSL-CM5A-LR forcing could not be validated against gauge data as the generated weather patterns were not set up to coincide with the historic weather. However, the rainfall correction required was quite similar as for the ERA-Interim_GPCP forcing (Table 1).

For the GGWM, the comparison with the GGWM-NHI showed large differences. The area influenced by the drawdown was much smaller for the GGWM compared to the GGWM-NHI (Fig. $3 \mathrm{a}$ and $\mathrm{b}$ ). This effect mainly depends on the high resistance of the aquitards. In the single layer GGWM, the major river systems act as a groundwater divide, whereas in the multilayered GGWM-NHI, groundwater can flow underneath the major rivers and affect the groundwater levels at other side of the river as well. The low saturated conductivity of the GGWM-NHI for the top soil provides less well yield and a smaller area of influence for

Table 1 Rainfall correction factors for the two climate forcings and Nash-Sutcliffe model efficiency coefficients for the predicted river runoff at three gauging stations considered in this study

\begin{tabular}{llllll}
\hline River & Station & study area & $\begin{array}{l}\text { Rainfall correction } \\
\text { factor ERA-Interim- } \\
\text { GPCP forcing }(-)\end{array}$ & $\begin{array}{l}\text { Nash-Sutcliffe coefficient } \\
\text { historic forcing } \\
\text { after calibration }\end{array}$ & $\begin{array}{l}\text { Rainfall correction } \\
\text { factor IPSL-CM5A- } \\
\text { LR forcing }(-)\end{array}$ \\
\hline Meuse & Lith & LRME & 0.81 & 0.58 & 0.86 \\
Rhine & Lobith & LRME & 0.77 & 0.58 & 0.84 \\
San Jacinto & Porter, TX & LBB & 0.97 & 0.09 & 0.97 \\
\hline
\end{tabular}

Time series and regime graphs are given in the supplementary material (Online Resource 1; Fig. S3) 


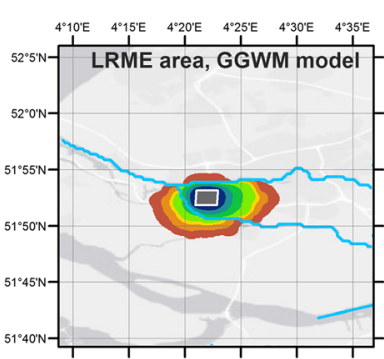

a)

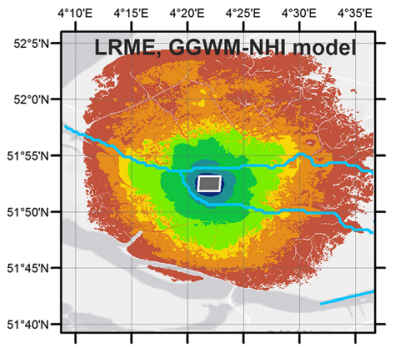

b)

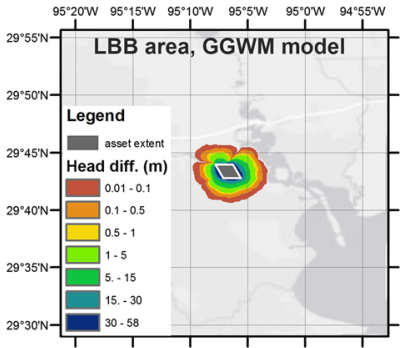

c)

Fig. 3 Modeled head differences for LRME (a, b) and LBB (c). Drawdown for LRME was $58 \mathrm{~m}$. The head differences for the GGWM (a) are more constrained by the river locations, and the regional effect on groundwater levels was limited as compared to the seven layer GGWM-NHI (b)

smaller drawdowns. Finally, the total transmissivity in the GGWM-NHI is approximately $2100 \mathrm{~m}^{2} /$ day for LRME (Table S3), and $600 \mathrm{~m}^{2}$ /day for the GGWM, which also explains the larger area of influence for the GGWM-NHI at large drawdowns.

The ratio of the GGWM-NHI well yields over the GGWM well yields showed significant differences between the different drawdown levels (Fig. S5). We found that the GGWM, compared to the GGWM-NHI, underestimated the well yields by a factor of around two for the drawdown levels of $29 \mathrm{~m}$ or more. This is due to the lower transmissivity in the GGWM. For the drawdowns between 0.5 and $14.5 \mathrm{~m}$ the GGWM well yields were overestimated, resulting from the omission of the highly resistive clay layers in the GGWM. Thin layers of low permeability can change well yields significantly, but such layers are not included in the GGWM as this detailed data is not globally available. The well yield comparison between the GGWM and the GGWM-NHI above clearly indicate that the absolute OGWA from the GGWM are highly uncertain, but time series based on a consistent model set up may still provide insight in relative changes.

\subsection{Operational Freshwater Availability Between 1980 and 2050}

\subsubsection{Time Series of OSWA and OGWA}

Figure 4 shows simulated time series of OSWA, OGWA and OWA for the period 1980-2065. OSWA (Fig. 4a and g) at LRME (Fig. 4a and d) shows no violations of EFR, even if set to a maximum value of $30 \%$ of the monthly regime graph. At LBB, the EFR are not met in 16 out of 1044 months for EFR at $10 \%$, and for 57 out of 1044 months for EFR at $30 \%$ (Fig. 4j). The $10 \mathrm{y}$ and $30 \mathrm{y}$ averaged OSWA showed a low inter-annual variation for LRME with a minimum OSWA of around $1600 \mathrm{~m}^{3} \mathrm{~s}^{-1}$ for EFR at $30 \%$ (Fig. 4b). The low inter-annual variation also strongly shows in the straightness of the cumulative river runoff (Fig. 4c). LRME showed a decline in OSWA of $50 \mathrm{~m}^{3} \mathrm{~s}^{-1}$ between 1980 and 2050. The OSWA at LBB shows a strong inter-annual variation (Fig 4g, h, and i). Average OSWA is $125 \mathrm{~m}^{3} \mathrm{~s}^{-1}$ with EFR at $10 \%$, but the $10 \mathrm{y}$ average OSWA varied between 95 and $180 \mathrm{~m}^{3} \mathrm{~s}^{-1}$, which showed that $10 \mathrm{y}$ average statistics are highly uncertain. Still, the 30y average OSWA did not show a clear trend for OSWA either at LBB, with a low OSWA around 2005 and the lowest around 2050. The low flows are also reflected in the cluster of EFR violations between 2050 and 2065 (Fig. 4j).

The cumulative river runoff for LBB (Fig. 4i) showed an interesting feature of the hydrological modeling. The river basin of the LBB asset showed that the pristine runoff (in 


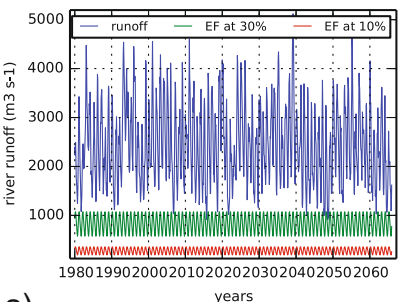

a)

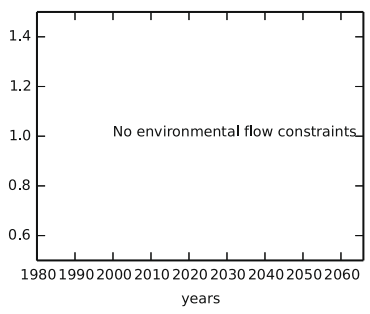

d)

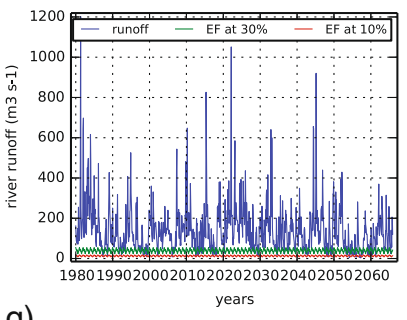

g)

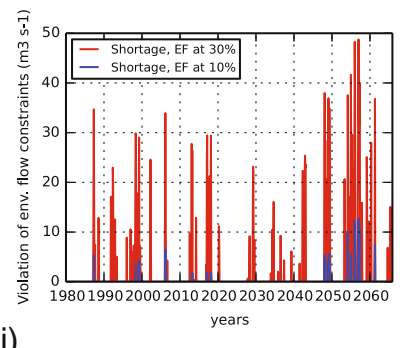

j)

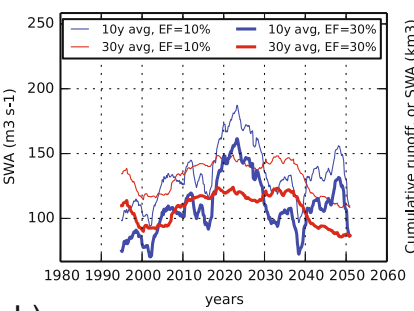

h)
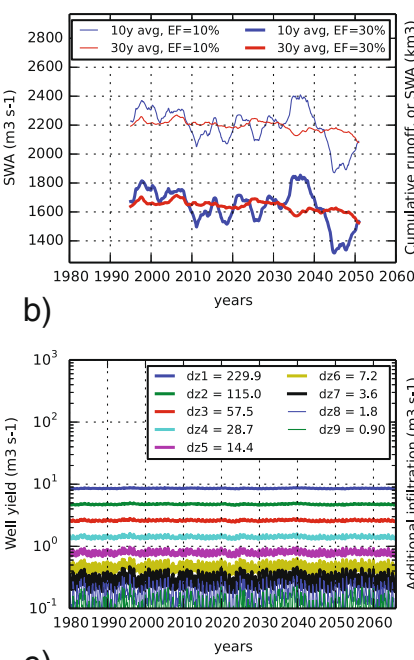

e)
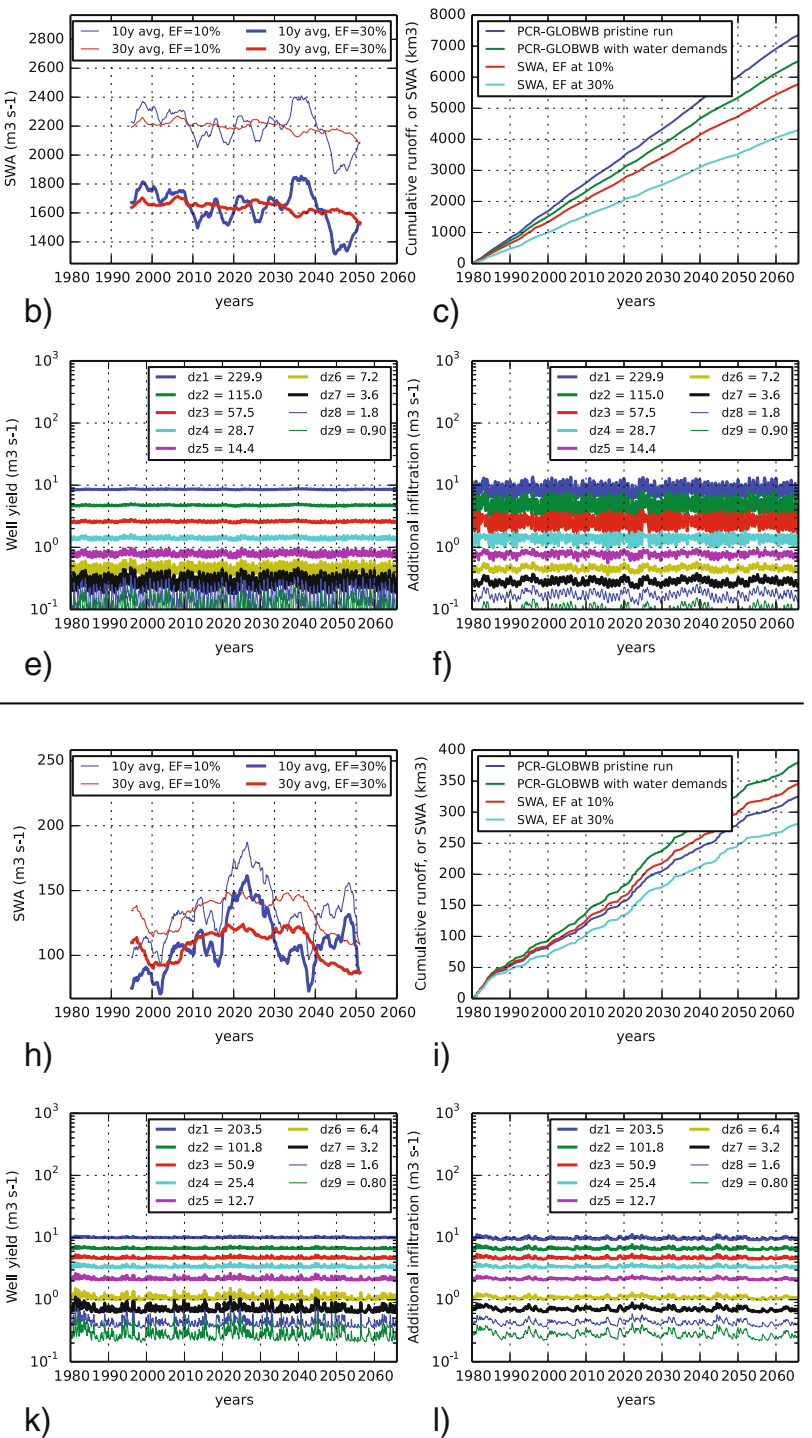

l)

Fig. 4 Modelled time series at LRME (a-f) and LBB ( $(\mathbf{g}-\mathbf{l})$. Time series were generated using PCR-GLOBWB and the GGWM models forced with the IPSL-CM5A-LR climate model using the RCP6.0 climate change scenario and the SSP2 socio-economic scenario. Environmental flow was set to $30 \%$ of the pristine discharge. Panels depict river runoff and environmental flow $(\mathbf{a}, \mathbf{g})$, averaged OSWA $(\mathbf{b}, \mathbf{h})$, cumulative OSWA (c, $\mathbf{i})$, monthly shortage of river flow $(\mathbf{d}, \mathbf{j})$, well yields $(\mathbf{e}, \mathbf{k})$, and additional infiltration of surface water due to groundwater extraction $(\mathbf{f}, \mathbf{l})$

dark blue) is exceeded by the modelled river runoff that includes the water demands in the basin (dark green line). This is caused by interbasin transfer of water, and the assumption in PCR-GLOBWB that fossil groundwater is always available in case of water shortage. Both mechanisms bring, by means of return flows additional water into the rivers, leading to more water in the river than can be expected from rainfall alone. This effect is less apparent in the regime graphs of the West Fork of the San Jacinto River as the largest water demands in the LBB basin are outside of the basin upstream of the gauging station. 
For OGWA, the well yields and additional infiltration of surface water due to the drawdown over the asset extent (Fig. 4e, f, k, and 1) represents the amount of water that can be extracted, but is not constrained by EFR. Well yields are presented here, instead of OGWA for visual clarity, as OGWA is zero for each month with EFR violations. This would only affect OGWA at LBB, as it is here that EFR are limiting OGWA (Fig. 4j). The infiltration shows a higher annual variation compared to the well yields, especially for LRME. However, very little interannual variation is present, and no long-term trend is apparent in these figures. Well yields ranged from 0.1 to $9 \mathrm{~m}^{3} \mathrm{~s}^{-1}$ for LRME, and from 0.2 to $10 \mathrm{~m}^{3} \mathrm{~s}^{-1}$ for LBB, depending on the depth of the drawdown.

\subsubsection{Regime Graphs of OSWA, OGWA, and OFWA}

Regime graphs of water availability were computed for three periods (around 1995, 2025, and 2050) and for two durations (10 and 30 years). For the latter two periods, the significance of the difference in mean with the first period is depicted by a round white-edged marker, which shows the months where the difference is significant at a $90 \%$ confidence level based on the paired sample Student's $t$-test.

The 30 year averaged OSWA regime graphs for LRME showed a significant change for the low flow months of September, October and November between period 1 (1981-2010) and period 3 (2036-2065) (Fig. 5a). In contrast, the 10 year averaged regime graphs did not show any significant changes (Fig. 5d). Between period 1 and 2, we did not find any significant changes at the $90 \%$ confidence level, except for October. The 30 year averaged regime graphs of OSWA for LBB showed a significant decline for the months of May and November between periods 1 and 3 (Fig. 5g). The 10 year averaged regime graphs showed a significant increase between period 1 and 2 for 4 months, but these changes were not sustained into period 3 (Fig. 5j). LBB also strongly showed the effect of EFR constraints on the $10 \%$ percentiles of the monthly OSWA (and OGWA), which increased from 4 months per year in period one to 11 months in period 3. As no river water, or groundwater, may be used during EFR violations, serious water shortage is projected to occur once every 10 years according to our definition of OSWA, and the $30 \%$ EF percentage.

The OGWA regime graphs for LRME did not show any significant changes over the modelling period (Fig 5b and e), in contrast to LBB (Fig. 5h and k). In LBB, the model showed a significant decline in OGWA for the months February, April, and May. The lowering of OGWA for period 3 strongly shows here in the $10 \%$ percentile of the OGWA regime graph, which goes to zero. The OFWA is dominated by OSWA for LRME and LBB. The difference is at least two orders of magnitude, which results in regime graphs of OFWA (Fig. 5c, f, i, and j) that are almost identical to those of OSWA. The dominance of OSWA for these two assets is logical as both locations are positioned at a location of relative abundance of surface water. For assets on the Arabian Peninsula for instance the situation would differ strongly.

\section{Discussion and Conclusion}

In this paper, we presented a rapid screening tool to quantitatively assess operational surface water availability and operational groundwater availability relevant to the operation of any asset with a temporal horizon of 2050. New aspects compared to existing methodologies include (1) precipitation-based correction of PCR-GLOBWB states and outputs using gauge 

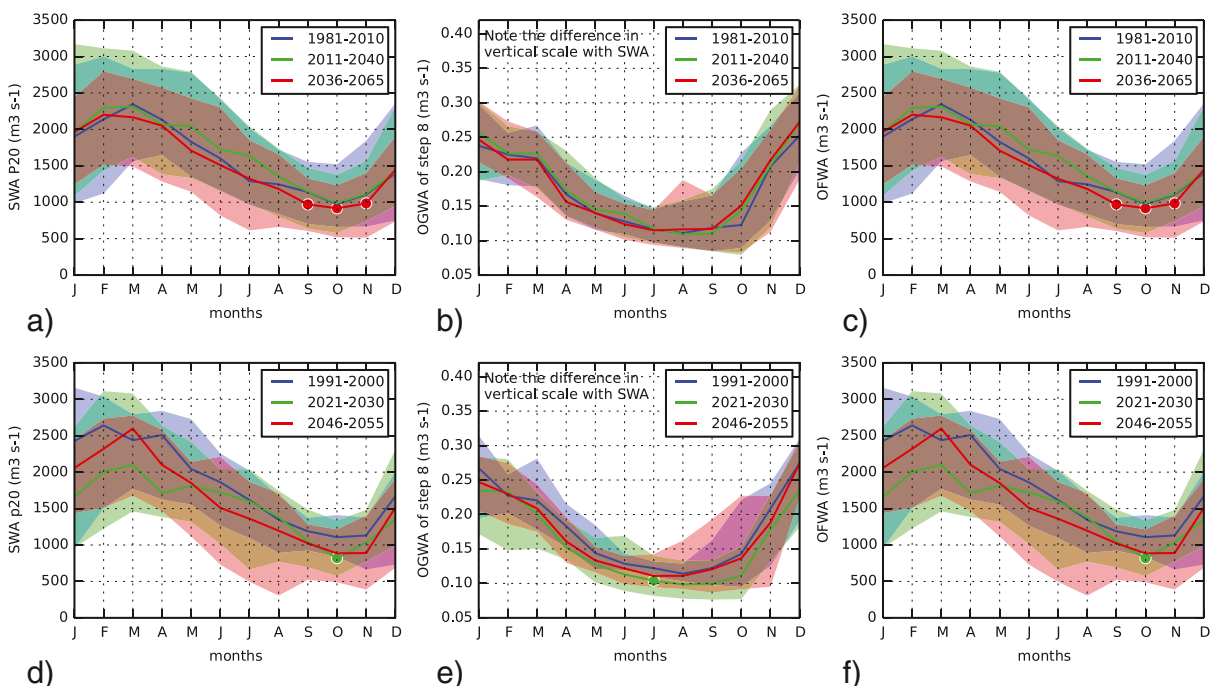

d)

e) f)
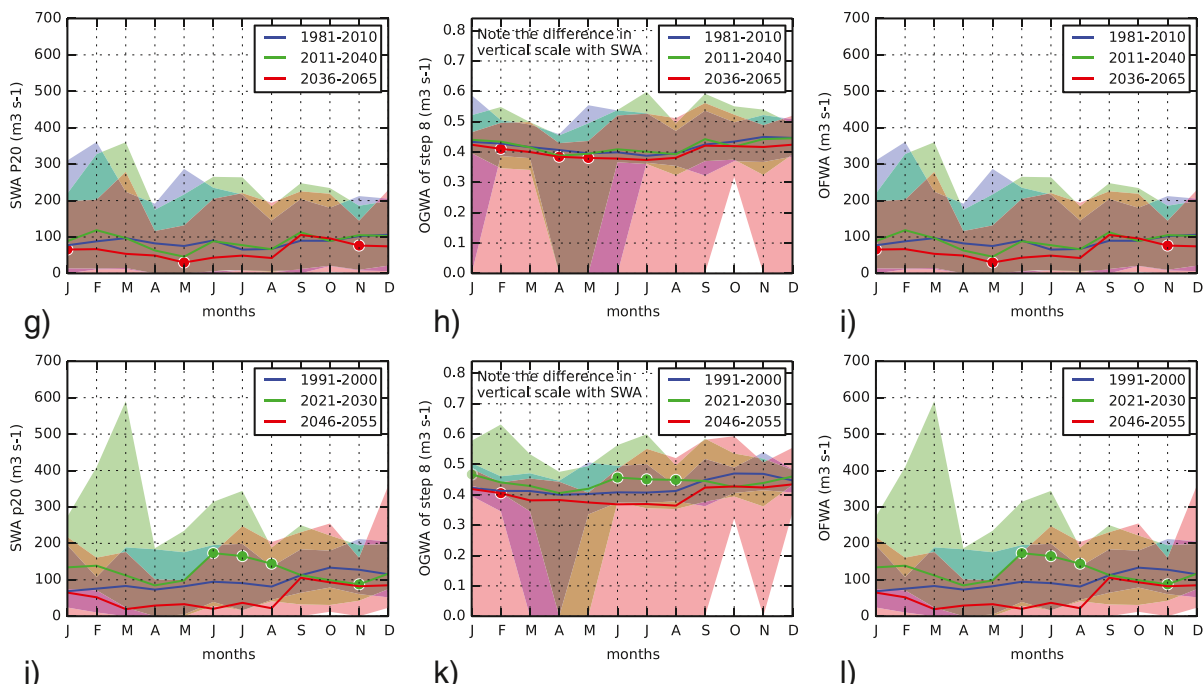

Fig. 5 Regime graphs of OSWA, OGWA, and OFWA for LRME (a-f) and LBB (g-l) study areas. Separate regime graps were computed using 30 year $(\mathbf{a}-\mathbf{c}$ and $\mathbf{g}-\mathbf{i})$ and 10 year $(\mathbf{d}-\mathbf{f}$ and $\mathbf{j}-\mathbf{-})$ time slices. Solid opaque lines represent the median water availability, the semi-transparent fill represents the interval between the 90 and $10 \%$ monthly percentile. The dots represent changes in monthly average discharge at $90 \%$ probability or more. OGWA regime graphs are based on the drawdown of step $8(1.8 \mathrm{~m})$. The same model forcings were used as for the output shown in Fig. 4. Panels depict 30y avg. OSWA (a, g), 30y avg. OGWA (b, h), 30y avg. OFWA (c, i), 10y avg. OSWA (d, j), 10y avg. OGWA (e, k), 10y avg. OFWA (f, l)

data, (2) defining environmental flow in a globally consistent way, (3) explicit definitions of 'operational surface water availability', 'operational groundwater availability' and 'operational freshwater availability', (4) inclusion of lateral groundwater flow modeling to quantify possible groundwater yields, now and in the future, (5) downscaling of PCR-GLOBWB output to $90 \mathrm{~m}$ resolution input for groundwater modeling, and (6) quantitative output on IPCC scenario-based trends in operational freshwater availability. 
The rapid screening methodology is suitable for intercomparison of OFWA on a like-forlike basis for potentially thousands of assets worldwide, as identical methods and input data are used. However, the consistency comes at a price of low accuracy for OGWA, which should be improved. A more exhaustive study could include more local knowledge, but it would be more time-consuming. The current project took around 4 months to complete, which would be too slow for strategic screening purposes. However, if the assessment would be automated further, additional assets could be screened within a week. A fully automated assessment would take around $36 \mathrm{~h}$ of computation time.

The operational relevance implies a small spatial extent as implemented, but also a high accuracy. The current version of PCR-GLOBWB, used to calculate operational surface water availability sufficed to produce operationally relevant volumetric metrics at a relevant scale: the correction factor for mean runoff ranged between 0.77 and 0.97 (Table 1). The NashSutcliffe model efficiency is in line with other validations of PCR-GLOBWB (Van Beek et al. 2011), with higher model efficiencies for larger catchments. As OSWA dominated OFWA for our two study areas, the OFWA estimates are operationally relevant. However, in areas that are dominated by operational groundwater availability more uncertainty will exist when determining the OFWA. Contrary to PCR-GLOBWB, the global groundwater model has only recently been developed by de Graaf et al. (2014), and the validation of this model was carried out on groundwater levels only. The current single-layer GGWM can be used to gain insight in long term trends in OGWA, but absolute OGWA remain highly uncertain. Nevertheless, the combination of PCR-GLOBWB and the GGWM does provide sufficient accuracy to distinguish between areas dominated by operational surface water availability and areas dominated by operational groundwater availability. This will narrow down the areas where investments in better global groundwater knowledge, like the presence of aquitards and the hydraulic conductivities of aquifers, will be justifiable for operational purposes, and thus focus the efforts and investments needed for further improvement of the rapid screening tool.

Decisions on the implementation of adaptation and mitigating measures are always taken under uncertainty. Projected changes of OFWA are based on output of scenarios, climate modeling, hydrological modeling, and groundwater modeling. Hence, uncertainty in modeling operational freshwater availability has more sources, and a full overview of uncertainty in OFWA should therefore include different scenarios at the expense of larger computational demands:

- Scenario uncertainty in RCP and SSP. The RCP and SSP scenarios are largely based on human behavior and projected socio-economic development. Knutti and Sedlacek (2013) assessed the uncertainty in the projected global temperature change in 2100 of the CMIP5 ensemble of models. They found a $3.2^{\circ} \mathrm{C}$ range in projected global average temperature between the four RCP scenarios.

- Model uncertainty in climate models. Knutti and Sedlacek (2013) found a range of at least $2{ }^{\circ} \mathrm{C}$ in the global average temperature projections for 2100 within a single RCP scenario.

- Model uncertainty in global hydrological models. Like the choice of the global climate model, the choice for a specific large-scale hydrological model also affects the final results. Prudhomme et al. (2014) carried out a multimodel comparison study of global hydrological models. Their computed drought index, the daily global deficit index (GDI), showed a coefficient of variation of approximately 0.15 for the RCP 6.0 scenario.

- Combined uncertainty in climate and hydrological models. Schewe et al. (2014) carried out an integrated assessment of five climate models and eleven hydrological models. They showed a strong spatial variation in the relative importance of both sources of uncertainty. 
The uncertainty derived from hydrological models is particularly dominant in many regions affected by declining water resources.

- Ungauged catchments. Calibration in this study has been carried out by adjusting rainfall based on observations of river runoff. In case of ungauged catchments, this method does not work. Two options to solve this are: (1) to use the correction factor of a neighboring catchment in case of regional patterns of correction factors, or (2) to leave out the correction step. In this study that would have meant a 3 to $23 \%$ overestimation, which is the overall error in mean river runoff. These results are in line with Van Beek et al. (2011); smaller catchments may have a larger error.

- Model uncertainty in groundwater models. The global hydrological model (de Graaf et al. 2014) consisted of a single layer. Compared to the GGWM-NHI, the GGWM over-predicted groundwater yield for large drawdowns, and underpredicted for small drawdowns due to lack of detail in the subsurface characteristics. The error in well yield was an order of magnitude. One way of improving well yield predictions would be to include local borehole data if these are available. Another area of improvement is the water level prediction from the downscaling. While this method uses the global terrain model with the highest detail available, it should be noted that it does not take backwater effects, or floodplain inundation into account. This might be solved using one-dimensional open water flow equations.

We developed and applied a new method to quantify location-specific hence operationallyrelevant predictions of freshwater availability on a like-for-like basis. Although the first implementation discussed here requires advancement, it can already be used to feed societal discussion on water availability, water risk assessments, and adaptation planning.

Open Access This article is distributed under the terms of the Creative Commons Attribution 4.0 International License (http://creativecommons.org/licenses/by/4.0/), which permits unrestricted use, distribution, and reproduction in any medium, provided you give appropriate credit to the original author(s) and the source, provide a link to the Creative Commons license, and indicate if changes were made.

\section{References}

2030WRG (2009) Charting our water future: economic frameworks to inform decision-making. 2030 Water Resources Group

Acreman MC, Dunbar MJ (2004) Defining environmental river flow requirements - a review. Hydrol Earth Syst Sci 8:861-876. doi:10.5194/hess-8-861-2004

Adler RF et al (2003) The version-2 Global Precipitation Climatology Project (GPCP) monthly precipitation analysis (1979-present). J Hydrometeorol 4:1147-1167. doi:10.1175/1525-7541(2003)004<1147:tvgpcp >2.0.co;2

Bierkens MFP (2015) Global hydrology 2015: state, trends, and directions. Water Resour Res. doi:10.1002/ 2015WR017173

Cai X, Rosegrant MW (2002) Global water demand and supply projections. Water Int 27:159-169. doi:10.1080/ 02508060208686989

de Graaf IEM, Sutanudjaja EH, van Beek LPH, Bierkens MFP (2014) A high resolution global scale groundwater model. Hydrol Earth Syst Sci Discuss 11:5217-5250. doi:10.5194/hessd-11-5217-2014

Döll P, Kaspar F, Lehner B (2003) A global hydrological model for deriving water availability indicators: model tuning and validation. J Hydrol 270:105-134. doi:10.1016/S0022-1694(02)00283-4

Dufresne JL et al (2013) Climate change projections using the IPSL-CM5 Earth System Model: from CMIP3 to CMIP5. Clim Dyn 40:2123-2165. doi:10.1007/s00382-012-1636-1

Falloon P, Betts R (2010) Climate impacts on European agriculture and water management in the context of adaptation and mitigation - the importance of an integrated approach. Sci Total Environ 408:5667-5687. doi:10.1016/j.scitotenv.2009.05.002 
Gain AK, Wada Y (2014) Assessment of future water scarcity at different spatial and temporal scales of the Brahmaputra river basin. Water Resour Manag 28:999-1012. doi:10.1007/s11269-014-0530-5

Gassert F, Landis M, Luck M, Reig P, Shiao T (2012) “Aqueduct global maps 2.0.” working paper. World Resources Institute, Washington, DC

Gleeson T et al (2011) Mapping permeability over the surface of the Earth. Geophys Res Lett 38:L02401. doi:10. 1029/2010gl045565

Gleeson T, Wada Y, Bierkens MFP, van Beek LPH (2012) Water balance of global aquifers revealed by groundwater footprint. Nature 488:197-200, doi:http://www.nature.com/nature/journal/v488/n7410/ abs/nature11295.html\#supplementary-information

Haddeland I et al (2014) Global water resources affected by human interventions and climate change. Proc Natl Acad Sci 111:3251-3256. doi:10.1073/pnas.1222475110

Hanasaki N et al (2008) An integrated model for the assessment of global water resources - part 1: model description and input meteorological forcing. Hydrol Earth Syst Sci 12:1007-1025. doi:10.5194/hess-12-1007-2008

Harbaugh AW, Banta ER, Hill MC, McDonald MC (2000) MODFLOW-2000, the U.S. Geological Survey modular ground-water model: user guide to mukularization concepts and the ground-water flow process. United States Geological Survey, Reston

Hartmann J, Moosdorf N (2012) The new global lithological map database GLiM: a representation of rock properties at the Earth surface. Geochem Geophys Geosyst 13:Q12004. doi:10.1029/2012gc004370

Huffman GJ, Adler RF, Bolvin DT, Gu G (2009) Improving the global precipitation record: GPCP version 2.1. Geophys Res Lett 36:L17808. doi:10.1029/2009g1040000

Idowu OA, Awomeso JA, Martins O (2012) An evaluation of demand for and supply of potable water in an urban centre of Abeokuta and Environs, Southwestern Nigeria. Water Resour Manag 26:2109-2121. doi:10. 1007/s11269-012-0006-4

Knutti R, Sedlacek J (2013) Robustness and uncertainties in the new CMIP5 climate model projections. Nature Clim Change 3:369-373, doi:http://www.nature.com/nclimate/journal/v3/n4/abs/nclimate1716. html\#supplementary-information

Lehner B (2011) Global Reservoir and Dam (GRanD) database, technical documentation, version 1.1 Global Water System Project Bonn, Germany

Nash JE, Sutcliffe JV (1970) River flow forecasting through conceptual models part I-a discussion of principles. J Hydrol 10:282-290. doi:10.1016/0022-1694(70)90255-6

Prudhomme $\mathrm{C}$ et al (2014) Hydrological droughts in the 21st century, hotspots and uncertainties from a global multimodel ensemble experiment. Proc Natl Acad Sci 111:3262-3267. doi:10.1073/pnas.1222473110

Schewe J et al (2014) Multimodel assessment of water scarcity under climate change. Proc Natl Acad Sci 111: 3245-3250. doi:10.1073/pnas.1222460110

Schornagel J, Niele F, Worrell E, Böggemann M (2012) Water accounting for (agro)industrial operations and its application to energy pathways. Resour Conserv Recycl 61:1-15. doi:10.1016/j.resconrec.2011.12.011

Sheffield J, Wood EF (2007) Characteristics of global and regional drought, 1950-2000: analysis of soil moisture data from off-line simulation of the terrestrial hydrologic cycle. J Geophys Res: Atmos 112:D17115. doi:10. 1029/2006JD008288

Souchon Y, Keith P (2001) Freshwater fish habitat: science, management, and conservation in France. Aquat Ecosyst Health Manag 4:401-412. doi:10.1080/146349801317276071

Taylor KE, Stouffer RJ, Meehl GA (2012) An overview of CMIP5 and the experiment design. Bull Am Meteorol Soc 93:485-498. doi:10.1175/bams-d-11-00094.1

Tennant DL (1976) Instream flow regimens for fish, wildlife, recreation and related. Environ Resour Fish 1:6-10. doi:10.1577/1548-8446(1976)001<0006:ifrffw $>2.0$. co;2

Tharme RE (2003) A global perspective on environmental flow assessment: emerging trends in the development and application of environmental flow methodologies for rivers. River Res Appl 19:397-441. doi:10.1002/rra.736

Van Beek LPH, Wada Y, Bierkens MFP et al. (2011) Global monthly water stress: 1. Water balance and water availability. Water Resour Res 47. doi: 10.1029/2010wr009791

Vermeulen PTM, Minnema B (2015) iMOD user manual. version: 3.01. Deltares, Utrecht, The Netherlands

Vörösmarty CJ, Green P, Salisbury J, Lammers RB (2000) Global water resources: vulnerability from climate change and population growth. Science 289:284-288. doi:10.1126/science.289.5477.284

Vuuren DP et al (2014) A new scenario framework for Climate Change Research: scenario matrix architecture. Clim Chang 122:373-386. doi:10.1007/s10584-013-0906-1

Wada Y, van Beek LPH, Viviroli D, Dürr HH, Weingartner R, Bierkens MFP (2011) Global monthly water stress: 2. water demand and severity of water stress. Water Resour Res 47:W07518. doi:10.1029/2010wr009792

WRI (2013) Aquaduct water risk atlas. World Resources Institute. http://www.wri.org/resources/maps/aqueductwater-risk-atlas. Accessed 13 July 2015 